\title{
The chemistry of vicinal tricarbonyls: An expedient route to fully-substituted 3- aminopyrroles
}

\author{
Phong M. Truong, Michael D. Mandler, Michael P. Doyle* \\ Department of Chemistry and Biochemistry, University of Maryland, College Park, Maryland 20742, United States of America \\ Dedication to Professor Harry Wasserman for his contribution to the chemistry of vicinal tricarbonyls
}

\section{ARTICLE INFO}

Article history:

Received

Received in revised form

Accepted

Available online

\section{Keywords:}

Vicinal tricarbonyl

2,3-Diketoester

3-Aminopyrroles

$\alpha$-Diazo- $\beta$-ketoesters

Multicomponent reaction

\section{ABSTRACT}

A one-pot, three-component reaction between a 2,3-diketoester, an imine, and an aldehyde, catalyzed by $p$-toluenesulfonic acid, produces fully-substituted 3-aminopyrroles that can be converted to pyrrolo[3,2-d]pyrimidine-2,4-dione.

2009 Elsevier Ltd. All rights reserved.

* Corresponding author. Tel.: +011-301-405-8388; fax: +011-301-314-2779; e-mail: mdoyle3@umd.edu 


\section{Introduction}

The highly electrophilic nature of the central carbonyl carbon in vicinal tricarbonyl (VTC) compounds allows for the versatile construction of new carbon-carbon bonds. ${ }^{1}$ Among others, ${ }^{2}$ Wasserman and coworkers have been pioneers in the applications of VTC compounds in organic syntheses. ${ }^{1 \mathrm{c}}$ Besides using VTC compounds for the synthesis of carbocyclic and heterocyclic frameworks, ${ }^{3}$ Wasserman and coworkers have demonstrated their importance in the synthesis of natural products and biological relevant compounds such as ( \pm -PS-5, ${ }^{4}$ prodigiosin, ${ }^{5}$ vasicine, ${ }^{6}$ papaveraldine, ${ }^{7}$ YM-47141, YM- $47142^{8}$ and others. ${ }^{9}$

Our research group has been focused on the chemistry of enol silyldiazoacetates of type $\mathbf{1}$ as a coupling partner with other electrophiles toward the synthesis of highly functionalized $\alpha$ diazo- $\beta$-ketoesters $2{ }^{10}$ We thought that oxidation of these complex diazo compounds $\mathbf{2}$ would give us access to functionalized VTC $\mathbf{3}$ that would allow us to study intramolecular reactions between the newly installed functional group and the central carbonyl (Scheme 1). This strategy allowed us to develop an efficient methodology to highly functionalized furans. ${ }^{11}$ Furthermore, we have reported the first diastereoselective ${ }^{12}$ and enantioselective ${ }^{13}$ nucleophilic addition reactions that occur at the central carbonyl carbon of VTC compounds.

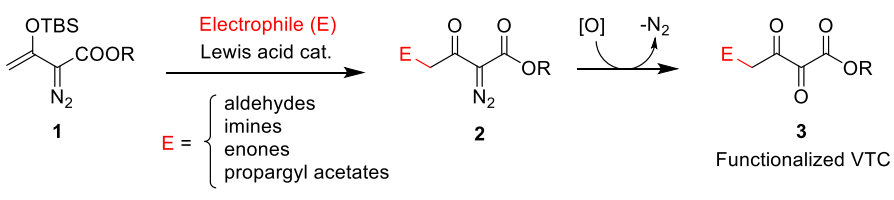

Scheme 1. Strategy to functionalize VTC 3.

We envisioned that a condensation reaction at the $\beta$-carbonyl of 2,3-diketoesters $\mathbf{3}$ with a primary amine would generate enamine 4 that can be viewed as a 1,3-dipolar equivalent species, as demonstrated by the resonance structures $\mathbf{A}$ and $\mathbf{B}$, for cycloaddition with other dipolarophiles. Herein, we wish to report an application of VTC $\mathbf{3}$ in an acid-catalyzed threecomponent reaction for the synthesis of highly substituted 3aminopyrroles 5, important nitrogen heterocycles present in natural products and biologically active compounds. ${ }^{14}$ Conventionally, multi-step syntheses were required for their preparation. ${ }^{15}$

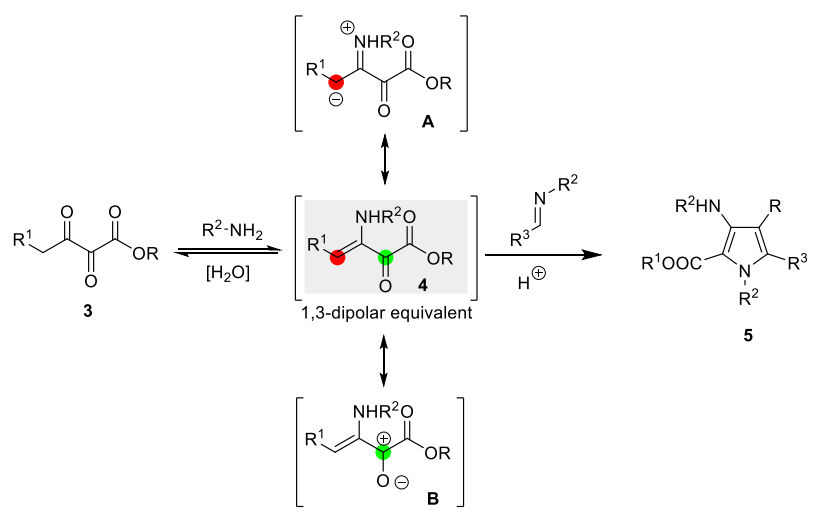

Scheme 2. Synthesis of 3-aminopyrroles.

\section{Results and Discussion}

Our synthesis began with a one-pot reaction involving benzyl 2,3-dioxobutanoate 3a, aniline, and benzaldehyde under acidcatalyzed conditions. Trifluoroacetic acid, $\mathrm{Zn}(\mathrm{OTf})_{2}$, and $p$ toluenesulfonic acid $(p$-TsOH) catalysis provided pyrrole 5a in
$65 \%, 50 \%$ and $71 \%$ yield, respectively (Table 1, Entries 2-4). Lowering the amount of $p$-TsOH to $10 \mathrm{~mol} \%$ did not have an effect on product yields. However, increasing the amount of $p$ TsOH to $50 \mathrm{~mol} \%$ and $100 \mathrm{~mol} \%$ decreased the formation of $\mathbf{5 a}$ to $55 \%$ and $20 \%$ yield respectively (Entries 6-7). These results indicate that complete protonation of aniline inhibited the reaction pathway. The reaction was elevated to a higher temperature by refluxing in toluene; however, a complex mixture was obtained due to decomposition of $\mathbf{3 a}$, and only a $12 \%$ yield of 5a was isolated (Entry 8). When the solvent was switched to THF, the desired pyrrole 5a was obtained in 94\% yield (Entry 9).

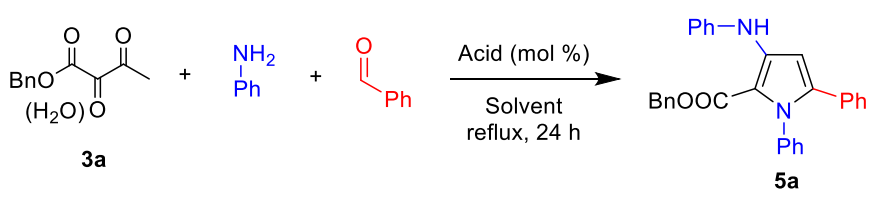

Table 1. Optimization of conditions for the synthesis of $\mathbf{5 a}^{a}$

\begin{tabular}{|c|c|c|c|}
\hline Entry & Acid (mol \%) & Solvent & Yield $(\%)^{[b]}$ \\
\hline 1 & none & DCM & 0 \\
\hline 2 & TFA (20) & DCM & 65 \\
\hline 3 & $\mathrm{Zn}(\mathrm{OTf})_{2}(20)$ & DCM & 50 \\
\hline 4 & $p$-TsOH (20) & DCM & 71 \\
\hline 5 & $p$-TsOH (10) & DCM & 70 \\
\hline 6 & $p$-TsOH (50) & DCM & 55 \\
\hline 7 & $p$-TsOH (100) & DCM & 20 \\
\hline 8 & $p$-TsOH (20) & Toluene & 12 \\
\hline 9 & $p$-TsOH (20) & THF & 94 \\
\hline
\end{tabular}

${ }^{\mathrm{a}}$ Reactions were performed on a $1.0 \mathrm{mmol}$ scale: A solution of 3a (1.2 eq.), aniline (2.1 eq.), benzaldehyde (1.0 eq.), and acid ( $\mathrm{X} \mathrm{mol} \mathrm{\% )} \mathrm{was} \mathrm{refluxed} \mathrm{in}$ $5 \mathrm{~mL}$ of solvent for $24 \mathrm{~h}$.

${ }^{\mathrm{b}}$ Isolated yield after column chromatography.

The proposed mechanism for the formation of 3-aminopyrrole 5a is given in Scheme 3. Enamine $4 \mathbf{a}$ and iminium ion $\mathbf{6}$ are generated in situ by condensation reactions of aniline with the $\beta$ carbonyl of 3a and benzaldehyde, respectively. Subsequent nucleophilic addition of enamine $4 \mathbf{a}$ to the iminium ion 6 produces intermediate $\mathbf{7}$, which cyclizes to the hemiaminal $\mathbf{8}$. The cyclic hemiaminal $\mathbf{8}$ tautomerizes to the enamine $\mathbf{9}$, and dehydration by 1,4-elimination generates the 3-aminopyrrole $\mathbf{5}$. THF appears to be sufficiently polar to promote the proton exchange reactions required in this transformation. Overall three components comprising four molecules are involved.

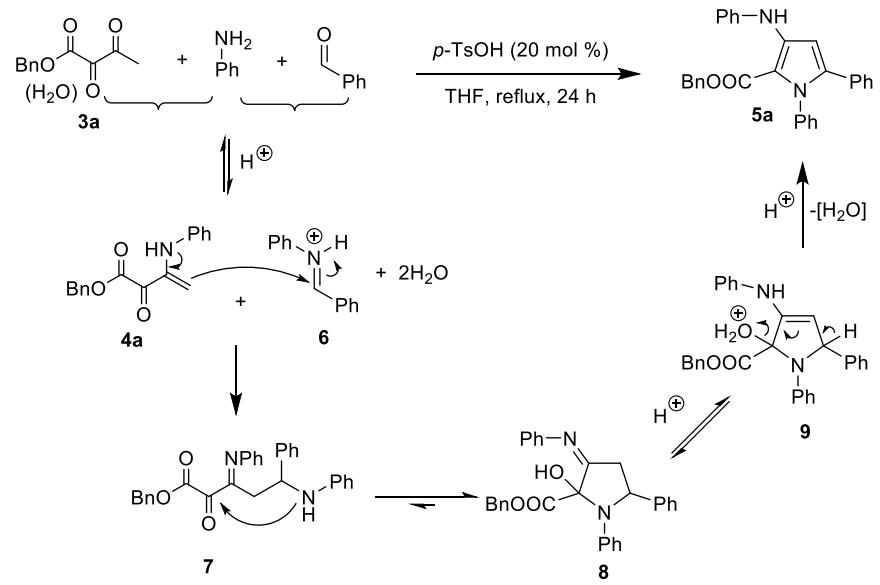

Scheme 3. Proposed mechanism for the formation of 3-aminopyrrole $5 a$. 
Table 2. Reaction substrate scope ${ }^{a}$

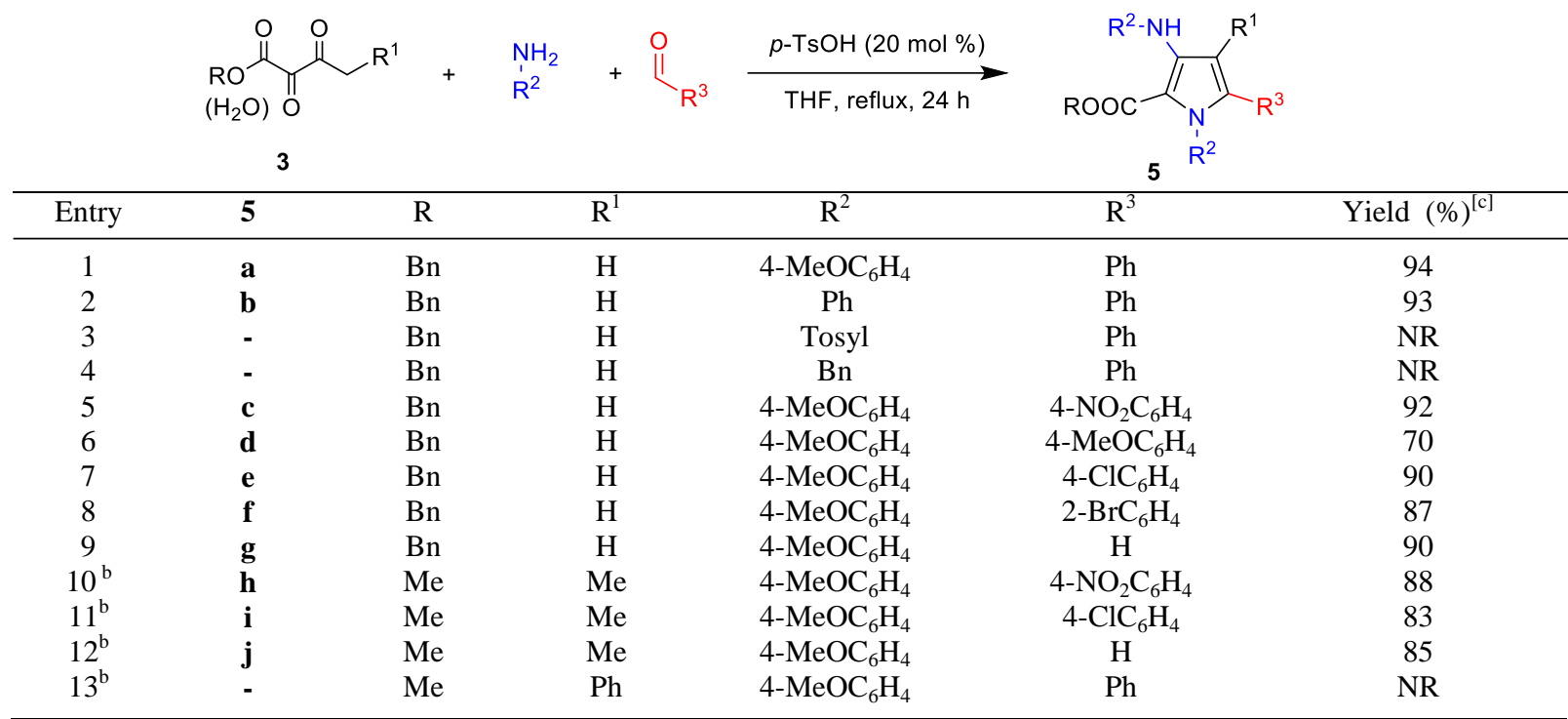

${ }^{\mathrm{a}}$ Reactions were performed on a $1.0 \mathrm{mmol}$ scale: A solution of $\mathbf{3}$ (1.2 eq.), aryl amine (2.1 eq.), aldehyde (1.0 eq.), and $p$-TsOH (20 mol \%) were refluxed in THF $(5 \mathrm{~mL})$ for $24 \mathrm{~h}$.

${ }^{\mathrm{b}}$ Reactions were run for $48 \mathrm{~h}$.

cIsolated yield after column chromatography.

The generality of this reaction was evaluated under the optimized conditions, and the results are reported in Table 2. $p$ Anisidine and aniline provided excellent yields of pyrroles 5a and 5b respectively (Table 2, Entries 1-2). Unfortunately, no reaction occurs when the less nucleophilic tosylamide or the more basic benzylamine is employed. The latter result is probably the consequence of base strength of benzylamine (Entries 3-4). Next, the reaction scope of the aldehyde was examined. The reaction tolerates a wide variety of aryl aldehydes including electron poor, halogen, ortho-substituted, providing excellent yields of 3-aminopyrroles. Electron rich-substituted aryl aldehydes provided the product in moderate yields (Entries $5-8)$. In addition, paraformaldehyde also provided $90 \%$ yield of the 5-H-3-aminopyrrole 5g (Entry 9). Examination of the $\mathrm{R}^{1}$ substituent of 2,3-diketoester $\mathbf{3}$ further demonstrated the broad applicability of this methodology to furnish fully substituted 3aminopyrroles. High yields were obtained when $\mathrm{R}^{1}=$ methyl, which allows for the installation of a methyl substituent at the C4 position (Entries 10-12). However, no reaction occurs when $\mathrm{R}^{1}$ $=\mathrm{Ph}$, probably due to the less reactive, conjugated enamine intermediate (Entry 13).

To demonstrate one use of 3-aminopyrroles, 5e was further reacted with phenylisocyanate for the synthesis of pyrrolo[3,2d]pyrimidine-2,4-dione 10 (Scheme 4). This structural motif that is a core structural feature of pyrrolo[3,2-d]pyrimidine-2,4-dione 11 that has been recently found to have remarkable high affinity and selectivity towards the $\alpha_{1}$-adrenoceptor, which controls smooth muscle in the cardiovascular system and the prostate. ${ }^{16}$

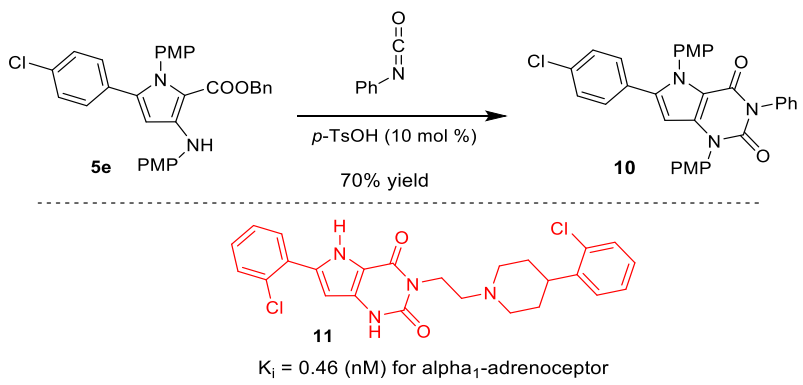

Scheme 4. Reaction of 3-aminopyrrole 5e with phenylisocyanate. $\mathrm{PMP}=p$-methoxyphenyl

\section{Conclusion}

We have developed a novel three-component reaction utilizing highly electrophilic 2,3-diketoesters for the synthesis of fully substituted 3-aminopyrroles, an important class of heterocyclic compounds that generally requires multi-step synthesis. ${ }^{14}$ This work illustrates the potential of 2,3-diketoesters as a 1,3-dipolar equivalent species that could be applicable for cycloaddition reactions with other dipolarophiles.

\section{Acknowledgments}

Support for this research from the National Science Foundation (CHE 1212446) is gratefully acknowledged. MDM thanks the Howard Hughes Medical Institute for an Undergraduate Research Fellowship at the University of Maryland.

\section{Supplementary Material}

Supplementary data associated with this article can be found in the online version.

\section{References and notes}

1. (a) Rubin, M. D. Chem. Rev. 1975, 75, 177-202. (b) Rubin, M.; Gleiter, R. Chem. Rev. 2000, 100, 1121-1164. (c) Wasserman, H. H.; Parr, H. Acc. Chem. Res. 2004, 37, 687-701.

2. (a) Salomon, M. F.; Pardo, S. N.; Salomon, R. G. J. Am. Chem. Soc. 1980, 102, 2473-2475. (b) Gill, G. B.; Idris, M. S. H.; Kirollos, K. S. J. Chem. Soc., Perkin Trans. 1 1992, 2355-2365. (c) Gill, G. B.; Idris, M. S. H. Tetrahedron 1993, 49, 219-234. (d) Beak, P.; Song, Z.; Resek, J. E. J. Org. Chem. 1992, 57, 944-947. (e) Brackeen, M. F.; Stafford, J. A.; Feldman, P. L.; Karanewsky, D. S. Tetrahedron Lett. 1994, 35, 1635-1638. (f) Adlington, R. M.; Baldwin, J. E.; Catterick, D.; Pritchard, G. J. J. Chem. Soc., Perkin Trans. 1 2000, 299-302. (g) Adlington, R. M.; Baldwin, J. E.; Catterick, D.; Pritchard, G. J. J. Chem. Soc., Perkin Trans. 1 2001, 668-679.

3. (a) Wasserman, H. H.; Cook, J. D.; Fukuyama, J. M.; Rotello, V. M. Tetrahedron Lett. 1989, 30, 1721-1724. (b) Wasserman, H. H.; Blum, C. A. Tetrahedron Lett. 1994, 35, 9787-9790. (c) Wasserman, H. H.; Lee, G. M. Tetrahedron Lett. 1994, 35, 97839786. (d) Wasserman, H. H.; Shiraishi, M.; Coats, S. J.; Cook, J. D. Tetrahedron Lett. 1995, 36, 6785-6788.

4. Wasserman, H. H.; Han, W. T. Tetrahedron Lett. 1984, 25, 37473750 . 
5. Wasserman, H. H.; Lombardo, L. J. Tetrahedron Lett. 1989, 30, $1725-1728$.

6. Wasserman, H. H.; Kuo, G.-H. Tetrahedron Lett. 1991, 32, 71317132.

7. Wasserman, H. H.; Amici, R.; Frechette, R.; Van Duzer, J. H. Tetrahedron Lett. 1989, 30, 869-872.

8. Wasserman, H. H.; Chen, J.-H.; Xia, M. Helv. Chim. Acta. 2000, $83,2607-2616$.

9. (a) Wasserman, H. H.; Rotello, V. M.; Krause, G. B. Tetrahedron Lett. 1992, 33, 5419-5422. (b) Wasserman, H. H.; Zhang, R. Tetrahedron 2002, 58, 6277-6283. (c) Wasserman, H. H.; Petersen, A. K.; Xia, M. Tetrahedron 2003, 59, 6771-6784.

10. (a) Doyle, M. P.; Kundu, K.; Russell, A. E. Org. Lett. 2005, 7, 5171-5174. (b) Zhou, L.; Doyle, M. P. Org. Lett. 2010, 12, 796799. (c) Liu, Y. Zhang, Y.; Jee, N.; Doyle, M. P. Org. Lett. 2008, 10, 1605-1608. (d) Qian, Y.; Shanahan, C. S.; Doyle, M. P. Eur. J. Org. Chem. 2013, 6032-6037.

11. Truong, P.; Xu, X.; Doyle, M. P. Tetrahedron Lett. 2011, 52, 2093-2096.

12. Truong, P.; Shanahan, C. S.; Doyle, M. P. Org. Lett. 2012, 14, 3608-3611.

13. Truong, P.; Zavalij, P. Y.; Doyle, M. P. Angew. Chem. Int. Ed. 2014, 25, 6586-6590.

14. (a) Almerico, A. M.; Cirrincione, G.; Aiello, E.; Dattolo, G. J. Heterocyclic Chem. 1989, 26, 1631-1633. (b) Unverferth, K.; Engel, J.; Hoefgen, N.; Rostock, A.; Guenther, R.; Lankau, H.-J.; H. J. Med. Chem. 1998, 41, 63-73. (c) Otmar, M.; Masojídková M.; Votruba, I.; Holý. A. Bioorg. Med. Chem. 2004, 12, 31873195. (d) Vooturi, S. K.; Cheung, C. M.; Rybak, M. J.; Firestine, S. M. J. Med. Chem. 2009, 52, 5020-5031. (e) You, X.; Xie, X.; Sun, R.; Chen, H.; Lia, S.; Liu, Y. Org. Chem. Front. 2014, 1, 940-946.

15. (a) Elliott, A. J.; Morris, P. E., Jr.; Petty, S. L.; Williams, C. H. J. Org. Chem. 1997, 62, 8071-8075. (b) Chen, N.; Lu, Y.; Gadamasetti, K.; Hurt, C. R.; Norman, M. H.; Fotsch, C. J. Org. Chem. 2000, 65, 2603-2605.

16. (a) Patanè, E.; Pittalà. V.; Guerrera, F.; Salerno, L.; Romeo, G.; Siracusa, M. A.; Russo. F.; Manetti, F.; Botta, M.; Mereghetti, I.; Cagnotto, A.; Mennini, T.; J. Med. Chem. 2005, 48, 2420-2431. (b) Carotti, A.; Cadavid, M. I.; Centeno, N. B.; Esteve, C.; Loza, M. I.; Martinez, A.; Nieto, R.; Ravinã, E.; Sanz, F.; Segarra, V.; Sotelo, E.; Stefanachi, A.; Vidal, B. J. Med. Chem. 2006, 49, 282299. 


\section{Graphical Abstract}

To create your abstract, type over the instructions in the template box below.

Fonts or abstract dimensions should not be changed or altered.

The chemistry of vicinal tricarbonyls: An expedient route to fully-substituted 3aminopyrroles

Phong M. Truong, Michael D. Mandler, Michael P. Doyle

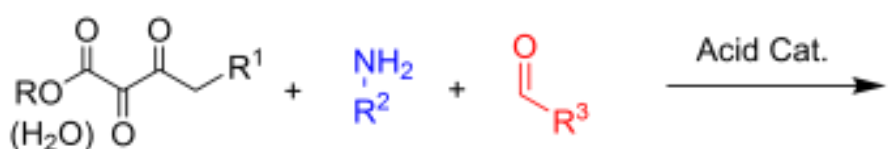

Leave this area blank for abstract info.

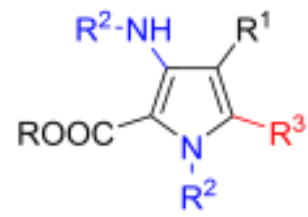

